\title{
Eye movement measurement in diagnostic assessment of disorders of consciousness
}

\author{
Windsor Kwan-Chun Ting ${ }^{1,2}$, Jose Luis Perez Velazquez ${ }^{2,3,4}$ and Michael D. Cusimano ${ }^{1,2,5,6}$ \\ 1 Injury Prevention Research Office, Keenan Research Centre for Biomedical Science, The Li Ka Shing Knowledge Institute, St. Michael's Hospital, Toronto, ON, \\ Canada \\ 2 Institute of Medical Science, University of Toronto, Toronto, ON, Canada \\ ${ }^{3}$ Neurosciences and Mental Health Programme, The Hospital for Sick Children, Toronto, ON, Canada \\ ${ }^{4}$ Department of Paediatrics, University of Toronto, Toronto, ON, Canada \\ ${ }^{5}$ Division of Neurosurgery, Department of Surgery, St. Michael's Hospital, Toronto, ON, Canada \\ ${ }^{6}$ Division of Neurosurgery, Department of Surgery, University of Toronto, Toronto, ON, Canada
}

\section{Edited by:}

Firas H. Kobeissy, University of

Florida, USA

Reviewed by:

Karim A. Sarhane, Johns Hopkins University, USA

Bruce G. Lyeth, University of

California Davis, USA

*Correspondence:

Jose Luis Perez Velazquez,

Neurosciences and Mental Health

Programme, The Hospital for Sick

Children, 555 University Avenue,

Toronto, ON M5G 1x8, Canada

e-mail: jose-luis.perez-velazquez@ sickkids.ca
We review the literature to appraise the evidence supporting or disputing the use of eye movement measurement in disorders of consciousness (DOC) with low levels of arousal or awareness, such as minimally conscious state (MCS), vegetative state (VS), and coma for diagnostic and prognostic purposes. We will focus on the effectiveness of each technique in the diagnostic classification of these patients and the gradual trend in research from manual to computerized tracking methods. New tools have become available at clinicians' disposal to assess eye movements with high spatial and temporal fidelity. The close relationship between eye movement generation and organic dysfunction in the brain allows these tools to be applied to the assessment of severe DOC as a unique supplementary toolset. We posit that eye tracking can improve clinical diagnostic precision for DOC, a key component of assessment that often dictates the course of clinical care in DOC patients. We see the emergence of long-term eye-tracking studies with seamless integration of technology in the future to improve the performance of clinical assessment in DOC.

Keywords: disorders of consciousness, eye movement, minimally conscious state, vegetative state, coma

\section{REVIEW}

\section{INTRODUCTION}

There are little means by which a clinician can assess and prognose clinical course in severe cases of disorders of consciousness (DOC), limiting effective care of patients. Furthermore, caregivers for DOC patients experience a higher level of anxiety, depression, and maladaptive psychological states compared with control participants and with themselves at the beginning of their caregiving period $(1,2)$. From both perspectives, it is important to have effective tools to make the best clinical decisions.

Disorders of consciousness are divided into several domains. Locked-in syndrome, minimally conscious state (MCS), vegetative state (VS), and coma are four major classifications (3). Each category of DOC is associated with its own clinical course and prognosis. Categorization of DOC has been repeatedly invaluable from a clinical perspective to make practical decisions about life support, palliative care, and/or treatment plan, but theory suggests that self-referential states such as consciousness are produced by coordinated diffuse network activations integrating multiple sets of different nuclei in the brain (4). If this is a reliable and accurate model, damage which significantly reduces consciousness will likely affect the brain areas necessary for successful eye movement. Quantifying this neurological damage may be useful and requires more than the simple qualitative appraisals of eye, sensory, and motor function.

The clinical gold standard for diagnosis of DOC is bedside behavioral assessment, in-hospital observation, and specialized robust scales such as the Coma Recovery Scale-Revised (CRS-R) (5), and neurocognitive assessment in advanced stages of recovery (6). Research has shown that neurophysiological monitoring may also be useful (7). The diagnosis from this assessment then dictates the clinical treatment plan and patient prognosis. However, it is difficult to make accurate decisions, partly due to the limited responsiveness and arousal of the patients, and partly due to the specialized training necessary to conduct a thorough neurological exam, and interpret neuroimaging and electrophysiology. A clinically standardized tool in the form of an eye movement measurement device, easily accessible and interpretable by all staff involved in the DOC patient's care would help to supplement patient care. There are estimates of up to $40 \%$ misdiagnosis rate between VS and MCS (8). Traditionally, eye assessment in DOC has been limited to simple assessment of eye response. An acute care physician may look at opening or closing of the eyes in response to stimuli, pupil response to light, blink reflex, or the direction of spontaneous movement as part of clinical workup depending on the level of consciousness of the patient. Beyond qualitative appraisal, however, there are many more parameters of eye movements, such as their velocity, accuracy, and error rate, which can be easily measured with the right machines and may provide valuable diagnostic and prognostic information that is not currently considered by physicians during clinical workup.

Published in 1974, the Glasgow Coma Scale (GCS) qualitatively assesses eye, motor, and verbal responses with a maximum score of 15 indicating full arousal and awareness (9). Despite being the 
most commonly used assessment of conscious state today (10), outcome measures for the eye response component are limited to eye opening or closing in response to simple stimuli (9). The GCS is an example where advanced eye-tracking technology can provide much richer and detailed information, which could be used in conjunction with existing techniques for more refined diagnosis and accurate prognosis of severe DOC. The GCS score is also an easily accessible system for all personnel involved in the patient's circle of care, and this has been reflected in the creation of clinical diagrams and visual flowcharts. Although no standardized equivalent exists for eye movements at the moment, as the technology is validated and more widely adopted, it is likely that similar resources would be created to lower the barrier to adoption for most health care personnel.

Further development of eye tracking and recording technology in the mid-1990s to sufficient temporal and spatial fidelity was needed before useful information could be obtained from recordings to make an informed assessment. Today, these eye trackers are commonplace in research of severe neurological disorders ranging from multiple sclerosis (11) to visuospatial neglect (12). The current research standard is the full desktop, which is limited in portability despite its power. Slowly, we are seeing the emergence of portable machines, which are worn on the head and able to measure eye movements on the sub-millisecond and sub-millimeter scale. Although this eye-tracking technology is used extensively in research, it is not used for clinical decision making.

The neuroanatomy responsible for many eye movements is well characterized in primates and humans (13-18). In humans, ocular motion is controlled by three sets of oculomotor muscles (15). Although they are the ultimate effectors of eye movement, computation for simple eye movements like saccades occurs over many levels of neural control connecting the cerebral cortices, through the midbrain structures, down to the lower brainstem where the desired eye movement is integrated and the final signal is issued (19).

Hence, an intricate connection exists between eye movement pathology and DOC. Generation of successful eye movements and a fully conscious state with high levels of arousal and awareness both depend on coordinated activity between multiple levels of neural control centers, including the cerebral cortex capable of modulating activity in most systems below it, the subcortical nuclei, midbrain and lower brainstem nuclei. Many studies have suggested that DOC may be reflected in eye movement pathology due to disruptions in these sensitive structural and functional connections.

Our knowledge of the neuroanatomy involved in DOC, although still young, has made great progress mainly through advances in functional neuroimaging of DOC patients (20, 21). Relatively novel techniques such as susceptibility/diffusion weighted imaging (S/DWI) and diffusion tensor imaging (DTI) have enhanced sensitivity to fine structural damage than canonical techniques (computerized tomography for example). Functional neuroimaging has quickly flourished and can assess transient fluctuations in regional cerebral blood flow and perfusion in the brain as well as functional integrity through neural connections, which may appear structurally intact otherwise. Advanced neuroimaging has been reviewed extensively as a tool to assess DOC and shows promise (20-25), but current clinical evaluation tools outside of neuroimaging remain limited in scope and power. Not all healthcare facilities have the financial resources and expertise to use neuroimaging for DOC assessment, but eye trackers are readily available, have lower cost of procurement, and are relatively more portable than MRI scanners. Eye movement measurement can therefore be a complementary evaluation tool for patients with severe DOC, or an alternative when the necessary neuroimaging resources are not available.

\section{VESTIBULO-OCULAR REFLEX}

The vestibular system and associated vestibulo-ocular reflex is well characterized (26). In DOC research, two different approaches have been used to elicit VOR. The traditional method is with caloric stimulation (27-33), in which warm or cold water is poured into the auditory canal unilaterally and quick phases of nystagmus are observed. Caloric VOR response has been associated with eventual recovery in several research and case studies (see Table $\mathbf{1}$ for details) $(28-30,33,34)$.

The second method involves electrical (galvanic) stimulation, in which the signal can be modulated based on the research question or clinical assessment goal, thus having a greater versatility than the traditional caloric stimulation method (34). This has been used by one group to assess patients in VS and MCS (34). They found that quantitative VOR response from galvanic stimulation recorded using a computer was able to stratify clinical outcome for a group of five comatose patients all with GCS of 3 on admission (34). Although only limited conclusions can be drawn from five cases, it illustrates the potential for computerbased eye tracking for measuring VOR in patients who have a low responsiveness and arousal. More studies are needed to demonstrate how specific these effects are between MCS and VS patients. Not all research positively suggested that VOR is effective in DOC assessment, however. Yagi and Baba (27) investigated 86 comatose patients using caloric VOR and auditory-brainstem responses (ABR) (an electrode-based measurement). They found that the $\mathrm{ABR}$ was more effective in predicting outcome in coma, but not all patients who were unable to exhibit VOR had a poor outcome (27). All considered, VOR could be a robust tool for assessment and prognosis in DOC, and is currently the eye measurement of choice compared to other movement types.

\section{VISUAL FIXATION AND PURSUIT}

Visual fixation and pursuit are the second most feasible measure of eye movement in DOC. Successful visual fixation is indicative of functional recovery (43). Furthermore, previous research have measured visual pursuit and tracking with high throughput eye trackers and there is evidence suggesting that VT performance can effectively differentiate between MCS and VS states. For example, Trojano et al. (35) conducted an experiment where moving shape stimuli were connected to a computerized eye tracker to assess the characteristics of visual tracking in 9 VS, 9 MCS, and 11 healthy control participants. They found that the proportion of off-target to on-target fixations were significantly different between the VS and MCS patients. Furthermore, there was a clear qualitative difference in the path of visual tracking between the three groups that could easily be identified by a clinician or nurse. Although simple 
Table 1 | Literature investigating eye movement measurement in disorders of consciousness

\begin{tabular}{|c|c|c|c|c|}
\hline Citation & Sample size and DOC & $\begin{array}{l}\text { Clinical utility } \\
\text { of eye movements } \\
\text { measurement }\end{array}$ & $\begin{array}{l}\text { Relevant eye } \\
\text { movement } \\
\text { measured }\end{array}$ & Primary relevant outcome \\
\hline Trojano et al. (35) & $9 \mathrm{VS} ; 9 \mathrm{MCS} ; 11 \mathrm{HC}$ & + & VT & $\begin{array}{l}\text { On-target fixation proportion is different between } \\
\text { MCS and VS }\end{array}$ \\
\hline Candelieri et al. (36) & $9 \mathrm{VS} ; 13 \mathrm{MCS}$ & + & VP & $\begin{array}{l}\text { VP elicited in } 62 \% \text { MCS but only } 33 \% \text { VS; VP activity } \\
\text { fluctuates over a day }\end{array}$ \\
\hline Dolce et al. (37) & $395 \mathrm{VS}$ & + & VT & $\begin{array}{l}\text { VT in } 73 \% \text { of VS patients; appearance of VT indicative } \\
\text { of higher GOS outcome }\end{array}$ \\
\hline Balazs et al. (39) & 14 PVS & + & SBEM & $\begin{array}{l}\text { PVS plus recovery patients show stronger pre-slow } \\
\text { ballistic eye movement gamma minimum than PVS } \\
\text { minus recovery patients }\end{array}$ \\
\hline Schlosser et al. (34) & 5 CO (All GCS 3) & + & Galvanic VOR & $\begin{array}{l}\text { Patient with no response to galvanic stimulation later } \\
\text { brain dead; patients with spontaneous and VOR } \\
\text { response to galvanic stimulus later recovered }\end{array}$ \\
\hline Oksenberg et al. (40) & $11 \mathrm{VS} ; 6 \mathrm{HC}$ & - & $\begin{array}{l}\text { Sleep REM } \\
\text { phasic activity }\end{array}$ & REM phasic activity in VS unrelated to recovery \\
\hline Born et al. (29) & $\begin{array}{l}109 \text { sustained LOC } \\
(\mathrm{GCS} \leq 7)\end{array}$ & + & $\begin{array}{l}\text { Oculocephalic } \\
\text { response, VOR }\end{array}$ & $\begin{array}{l}\text { Via logistic discriminant analysis of outcome, } \\
\text { integration of VOR into assessment improves } \\
\text { outcome prediction at } 6 \text { months }\end{array}$ \\
\hline Yagi and Baba (27) & $86 \mathrm{CO}$ & - & Caloric VOR & $\begin{array}{l}\text { Auditory-Brainstem Response (non-eye) was more } \\
\text { effective than caloric VOR in prognosis of CO patients. } \\
\text { Furthermore, not all patients who lacked VOR } \\
\text { response had poor outcome }\end{array}$ \\
\hline Braakman et al. (41) & $305 \mathrm{CO}$ & + & $\begin{array}{l}\text { Reflex and } \\
\text { spontaneous } \\
\text { reflex eye } \\
\text { movement }\end{array}$ & $\begin{array}{l}\text { Reflexive and spontaneous eye movement is } \\
\text { predictive, along with age in decades, duration of } \\
\text { coma, GCS score, and pupillary response of GOS } \\
\text { outcome in CO patients } 6 \text { months later }\end{array}$ \\
\hline \multicolumn{5}{|c|}{ SECTION 2: CASE STUDIES/SERIES AND LETTERS } \\
\hline Trojano et al. (42) & $\begin{array}{l}13 \text { VS/UWS, } 13 \text { MCS; } \\
13 \mathrm{HC}\end{array}$ & + & VT & $\begin{array}{l}\text { MCS patient ratio of on-target:off-target fixation for } \\
\text { pictures of participants' relatives higher than circle or } \\
\text { parrot stimulus. Proportion of on-target fixation in VS } \\
\text { below chance; in MCS above chance }\end{array}$ \\
\hline
\end{tabular}




\section{Table 1 | Continued}

\begin{tabular}{|c|c|c|c|c|}
\hline Citation & Sample size and DOC & $\begin{array}{l}\text { Clinical utility } \\
\text { of eye movements } \\
\text { measurement }\end{array}$ & $\begin{array}{l}\text { Relevant eye } \\
\text { movement } \\
\text { measured }\end{array}$ & Primary relevant outcome \\
\hline Schnakers et al. (43) & $\begin{array}{l}60 \text { post-CO; of these, } \\
29 \text { VS, } 7 \text { MCS }\end{array}$ & + & CRS-R & $\begin{array}{l}\text { Scaled assessment of visual tracking in CRS-R more } \\
\text { sensitive than FOUR score, identified seven more } \\
\text { patients who were in MCS }\end{array}$ \\
\hline Kane et al. (44) & $60 \mathrm{CO}$ & + & $\begin{array}{l}\text { Ocular } \\
\text { micro-tremor }\end{array}$ & $\begin{array}{l}\text { Oculogram Grade (OG) (based on graded assessment } \\
\text { of conjunctive micro-tremor) positively correlated with } \\
\text { GCS score at time of assessment and GOS outcome } \\
\text { at } 3 \text { months }\end{array}$ \\
\hline Leigh et al. (28) & $6 \mathrm{CO}, 4 \mathrm{PVS}, 6 \mathrm{HC}$ & + & $\begin{array}{l}\text { Oculocephalic } \\
\text { response brought } \\
\text { by VOR }\end{array}$ & $\begin{array}{l}\text { Post-VOR midline drift time constant } \geq 10 \mathrm{~s} \text { in } \mathrm{HC} \text {; } \\
\leq 1.5 \mathrm{~s} \text { in } \mathrm{sLoC} ; \leq 0.5 \text { in PVS }\end{array}$ \\
\hline van Woerkom et al. (45) & $\begin{array}{l}1 \mathrm{CO} ; 60 \mathrm{TBI} \text { patients } \\
\text { later in } \mathrm{DOC}\end{array}$ & + & $\begin{array}{l}\text { Caloric } \\
\text { nystagmus }\end{array}$ & $\begin{array}{l}\text { Abnormal saccadic oscillations in } 10 \mathrm{TBI} \text { patients } \\
\text { associated with poor GOS } 1 / 6 \text { months post-injury }\end{array}$ \\
\hline
\end{tabular}

MCS, minimally conscious state; VS, vegetative state; PVS, persistent vegetative state; UWS, unresponsive wakefulness syndrome; CO, comatose state; sLoC,

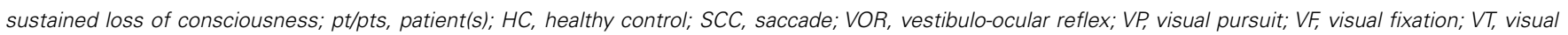
tracking; SBEM, Slow Ballistic Eye Movement; REM, Rapid Eye Movement; NY, Nystagmus; [N], Neutral; TBI, traumatic brain injury; GCS, Glasgow Coma Scale; GOS, Glasgow Outcome Score; FOUR, Full Outline of UnResponsiveness Scale; CRS-R, Coma Recovery Scale-Revised.

assessment of visual fixation does not require eye-tracking technology, this is an example of how the technology can help make assessments more precise, accurate, and effective.

Candelieri et al. (36) studied visual pursuit in 9 VS and 13 MCS patients using the scaled CRS-R, and found that in $63 \%$ of MCS patients effective visual pursuit could be elicited, whereas only $33 \%$ of VS patients were able to initiate them. They were also one of the first to report that visual pursuit performance fluctuates over the day in DOC patients. Finally, a study by Bruno et al. (38) coupled advanced neuroimaging with scaled visual tracking as measured by the CRS-R. They found that patients in the VS had altered metabolic function in PET neuroimaging compared with the healthy control group. Studies discussed here, which quantitatively measured visual tracking behavior, used simple measures such as the proportion of successful visual tracking time on-target or off-target. However, many other variables can be obtained from a computerized trace, and future studies could delve more deeply to identify more sensitive and specific biomarkers of conscious state in these patients with the data obtained from the eye-tracking technology.

\section{SACCADES AND RAPID EYE MOVEMENTS}

Rapid eye movements (REMs) such as saccades allow us to quickly focus on objects in our environment. The saccadic generation system is well characterized in humans $(13,14,16)$. Signal generation and final integration of the oculomotor command takes place in the brainstem, but upstream modulatory centers in the midbrain (superior colliculi) and cerebral cortices (frontal and parietal eye fields) play critical roles in the accurate generation of different types of saccades $(19,46)$. Saccades can be generated from memory, in response to novel visual stimuli, or directed away from a certain novel visual stimulus (19). The saccadic system is well integrated between different levels of neural control. Furthermore, highly portable saccadometers have been designed that can be worn on the patient's head, with the visual stimulus projected onto a white wall (47).

Saccades would be the ideal system of eye movement to measure, since they are readily quantifiable and have mapped neuroanatomical substrates. However, reliable measurement of saccades in response to memory or novel visual stimuli is difficult in DOC patients because many experimental paradigms require conscious awareness. There has been little research looking specifically at saccadic measures in DOC, except for quick saccadic oscillations (39). Microsaccades (small involuntary jerks of the eye) may be useful as an alternative for eye movement assessment of visual attention in the future (48-50), but their role in DOC, if any, have yet to be established.

\section{OTHER EYE MOVEMENTS - QUICK PHASES OF NYSTAGMUS, OCULAR MICRO-TREMORS, REM}

Nystagmus is an involuntary eye movement associated with saccades requiring little cortical integration, which has been used in the assessment of DOC patients after VOR stimulation (45). Ocular micro-tremors (discussed in more detail below) have also been investigated in DOC patients with analog machinery, but not with computerized eye-tracking software (44). Very few research studies have measured REM during sleep in VS patients. Oksenberg et al. (40) conducted a study with 11 VS and 6 healthy control participants, but did not find a significant relationship with recovery (40).

\section{VALIDATION OF EYE MOVEMENT MEASUREMENT IN DOC}

Only one study was found to assess reliability of eye movement measurement in DOC, and no studies assessing validity were 
identified. van den Berge et al. (31) assessed the inter-rater reliability of vestibulo-ocular reflex monitoring in 30 comatose patients (31). This study used a scaled measure of VOR from one (no reaction) to four (full nystagmus). The VOR responses were recorded on film and analyzed after the experiment by experienced neurologists. The kappa (inter-rater reliability) ratings for spontaneous eye movements and oculocephalic responses were 0.46 and 0.49 , respectively indicating moderate agreement (31). More studies investigating the sensitivity, specificity, reliability, and validity of eye movements measurement in DOC patients are required if these methods are to gain widespread acceptance in medical practice.

\section{CASE STUDIES, CASE SERIES, AND LETTERS}

Overall, there have been few clinical case studies and letters investigating eye movement measurement in DOC. Trojano et al. (42) conducted a study in which $13 \mathrm{VS}, 13 \mathrm{MCS}$, and 13 healthy control participants viewed circles, parrot pictures, and pictures of their relatives as stimuli in an eye-tracking paradigm for visual pursuit and tracking (42). They found that in MCS patients, the ratio of on-target to off-target fixations for pictures of their relatives was higher than for the other two stimuli, indicating there is some visual processing and affective salience associated with the picture that is not present in VS patients (42). A natural progression from this study would be to investigate multi-sensory stimuli, which may combine auditory and visual domains, for example, for a more nuanced approach and enhanced sensitivity to detect differences between MCS and VS patients.

Schnackers et al. conducted a study in 2006 in which 60 postcomatose patients (of these, $29 \mathrm{VS}$ and $7 \mathrm{MCS}$ ) were graded according to the CRS-R. They found that scaled assessment of visual tracking was more sensitive in the CRS-R to outcome than the Full Outline of UnResponsiveness (FOUR) score, which has less detailed eye response assessment (43). Here, we see the advantage of scaled assessment over simple appraisal of eye movement; a similar advantage can be gained when considering electronic eye movement measurement over scaled responses.

Kane et al. (44) reported a case series of 60 comatose patients whose ocular micro-tremor was assessed using an electrooculogram. By creating an "oculogram score" from the recorded eye tracings based on the level of conjunction of eye movement, they correlated ocular micro-tremor activity with GCS score at time of recording and GOS score at 3 months, with positive results (44). Leigh et al. (28) found that temporal characteristics of the post-VOR midline drift back to center could differentiate healthy controls, patients in persistent VS, and coma (28). As early as 1984, van Woerkom et al. reported that abnormal saccadic oscillations associated with caloric stimulation in TBI patients was associated with poor GOS outcome 1 and 6 months post-injury (45). Most of these examples have shown that quantitative measurement of eye movements has clinical utility either in diagnosing DOC or in assessing long-term prognosis of these patients. Table 1 summarizes our findings.

\section{TRENDS IN EYE-TRACKING TECHNOLOGY}

All types of eye movement responses are easily measured using a modernized computerized eye tracker, including VOR, visual fixation, smooth pursuit, nystagmus, and saccades. Commercial companies have developed advanced eye-tracking systems for use in research, such as the EyeLink ${ }^{\circledR} 1000$ by SR Research (51) or the IVIEW XTM High Speed Eye Tracker by SensoMotoric Instruments (52). These high speed advanced eye trackers are able to measure many parameters at once with sub-millisecond temporal resolution and spatial precision to within a 10th of a degree, all with sampling frequencies in the thousands of hertz (51). Recent developments such as the IRIS Infrared Limbus Eye Tracker (53) by Skalar and the Portable Saccadometer by Ober Consulting (47) have introduced head-mounted eye tracking, which increases portability of the instrument and feasibility for clinical adoption. Many of the advanced systems are programable and the portable units allow measurement parameters (i.e., stimulus latency, location, frequency) to be tailored for clinical applications.

With technological progress, we have been able to measure spontaneous eye movements or ocular responses to stimuli with greater accuracy and precision. Since the 1990s, analog eyetracking technology such as the electrooculograph has gradually been replaced by digital methods connected to high throughput computers. Furthermore, a clear trend has emerged toward miniaturization and enhanced temporal/spatial fidelity. Over time, these trends are expected to continue, such that advanced eye tracking will be easier to integrate into clinical practice by eliminating physical barriers such as size and portability while maintaining high quality for research or clinical applications. We expect these trends to continue with advances in wearable consumer technology (e.g., Google Glass analogs, fitness trackers, smartwatches).

\section{RESEARCH PERSPECTIVES AND FUTURE DIRECTIONS}

Currently, there are a limited number of studies supporting these measurements in clinic environment, and only one validation study has been found in MEDLINE. Despite this, the available evidence is compelling. The results of the literature review suggest that majority of the eye movement recording conducted in research currently are limited to VOR or other simple responses, which are quick to conduct, quantify, and interpret. In the future, however, as battery life associated with portable technology is extended, we should see the emergence of long-term eye-tracking studies, which may detect patterns over extended periods of time (over the course of several days, weeks, or months) unfeasible with current devices. This will open new domains in research and clinical decision making for these patients, since patterns may emerge from protracted, natural eye-tracking recording in patients, which is not detectable in short timepoints.

\section{PRACTICAL PERSPECTIVES}

Currently used approaches such as the GCS or the FOUR score are effective and are simple and quick enough to perform while still being sufficient to make diagnostic decisions. The eye trackers that are clinically useful today, much like the useful computers of several decades ago, are large and unwieldy, requiring the patient to be in a specific body position (e.g., sitting upright) and are not suited for use in patients with secondary neck injuries due to head trauma (limited neck movement). With more robust research, results supporting the use of eye tracking in assessing DOC in the future, in tandem with the miniaturization trends discussed earlier, we see that the practical benefits of improved outcome assessment will 
outweigh the costs associated with adopting new technology and framework for assessment. Neuroimaging went through a similar process from clinical acceptance to adoption since its development several decades ago, but it is now part of routine clinical assessment and care. A similar level of research and development needs to take place for advanced eye measurement in DOC patients moving forward. Currently, another important barrier to clinical adoption include limited validation studies demonstrating the diagnostic power of eye movement measurement in DOC, as discussed earlier. These developments and studies will likely need to take place before we can expect to see widespread clinical adoption of eye movement assessment.

The clinical and research ethics councils in health organizations need to discuss issues of patient consent and develop a framework for deployment of these tools, but integration of eyetracking measurement tools should not completely replace what is currently available. There is critical value in the clinical assessment and the physician's appraisal of conscious state. Although eye movement measurements may prove to be an effective diagnostic tool, training critical care physicians and nurses for more thorough neurological examinations and clinical expertise is still very important and is likely to have the largest immediate impact on reducing misdiagnosis rate. A clinician's judgment obtained from time-tested tools should not be replaced, but further augmented by this technology. In the final analysis, integration and adoption of eye-tracking tools and methods should not be a barrier, but rather a helpful aid toward better care and reduction of misdiagnosis for any patient in a DOC.

\section{LIMITATIONS}

There are limitations to our literature search and interpretation. We only reviewed results from Ovid MEDLINE. Study quality was not systematically assessed. Diagnostic randomized controlled trials were not found (54), which might identify whether eye-tracking assessment provides any advantage over the contemporary gold standard of behavioral assessment. Finally, there were very few studies which quantitatively assessed the prognostic ability of eye tracking in DOC (see Table 1). Although some studies performed correlational analyses between measurement and GOS outcome, more studies along this avenue are needed to see if eye tracking has any prognostic relevance or if it is only useful as a diagnostic classifier.

\section{CONCLUSION}

\section{AN INTEGRATED PERSPECTIVE}

Richer information about how eye movement/response is affected will be instrumental in advancing clinical assessment of DOC in the future. As medical technology becomes quicker, more accurate, and miniaturized, the integration of advanced measurement tools like the ones discussed into our daily lives will quickly become seamless. It is imperative, therefore, that a clinical framework be set in place early so that the implementation of these tools in medicine is not a barrier unto itself. Creating a strategic plan integrating economic, research, logistic, and ethical aspects is essential for successful transition from simple appraisals of eye response, through scaled assessment of eye movement, to widespread adoption of quantitative eye measurement by the bedside.

\section{A VISION FOR THE FUTURE}

We can envision a future in which technology to measure eye movements is embedded into the process of medicine so well that it becomes invisible - physicians will have crucial human interactions with patients, but their judgment will be aided by semiautonomous measurement machines, which track eye movements over their entire stay in the hospital, and generate a report with recommended diagnostics and projected clinical outcome. Clinical decision making can be augmented through a standardized and validated scale based on simplifying heuristics obtained from the eye-tracking device. All of this tracking will be conducted with minimal physician input. The eye-tracking machine itself could take the form of a wireless contact lens that the patient wears, offering the optimum combination of portability, power, sensitivity, and non-invasiveness. This vision may not be too far off - innovators in silicon valley have already developed eye-tracking add-ons for Google Glass, the de facto vanguard in wearable computing today (55).

In conclusion, research evidence supports integration of quantitative eye movement measurement in improving diagnostic precision in of DOC. However, more validation studies are required to assess prognostic relevance of eye tracking. It will also require a coordinated effort between disciplines between frameworks of medicine and research to bring this beneficial assessment methodology to clinical care of DOC.

\section{AUTHOR CONTRIBUTIONS}

Windsor Kwan-Chun Ting: "substantial contributions to the conception or design of the work; drafting the work; final approval of the submitted version; agrees to be accountable for all aspect of the work and ensures that any questions related to the accuracy or integrity of any part of the work are appropriately investigated and resolved." Dr. Jose Luis Perez Velazquez: "substantial contribution to the conception of the work; critically revising the work for important intellectual content; final approval of the submitted version; agrees to be accountable for all aspect of the work and ensures that any questions related to the accuracy or integrity of any part of the work are appropriately investigated and resolved." Dr. Michael D. Cusimano: "substantial contribution to the conception of the work; critically revising the work for important intellectual content; final approval of the submitted version; agrees to be accountable for all aspect of the work and ensures that any questions related to the accuracy or integrity of any part of the work are appropriately investigated and resolved."

\section{REFERENCES}

1. Leonardi M, Giovannetti AM, Pagani M, Raggi A, Sattin D, National Consortium Functioning and Disability in Vegetative and in Minimal Conscious State Patients. Burden and needs of 487 caregivers of patients in vegetative state and in minimally conscious state: results from a national study. Brain Inj (2012) 26:1201-10. doi:10.3109/02699052.2012.667589

2. Moretta P, Estraneo A, De Lucia L, Cardinale V, Loreto V, Trojano L. A study of the psychological distress in family caregivers of patients with prolonged disorders of consciousness during in-hospital rehabilitation. Clin Rehabil (2014) 28:717-25. doi:10.1177/0269215514521826

3. Owen AM. Disorders of consciousness. Ann N Y Acad Sci (2008) 1124:225-38. doi:10.1196/annals.1440.013

4. Di Perri C, Stender J, Laureys S, Gosseries O. Functional neuroanatomy of disorders of consciousness. Epilepsy Behav (2014) 30:28-32. doi:10.1016/j.yebeh. 2013.09.014 
5. La Porta F, Caselli S, Ianes AB, Cameli O, Lino M, Piperno R, et al. Can we scientifically and reliably measure the level of consciousness in vegetative and minimally conscious States? Rasch analysis of the coma recovery scale-revised. Arch Phys Med Rehabil (2013) 94(527-535):e521. doi:10.1016/j.apmr.2012.09.035

6. Amantini A, Carrai R, Fossi S, Pinto F, Grippo A. The role of early electroclinical assessment in improving the evaluation of patients with disorders of consciousness. Funct Neurol (2011) 26:7-14.

7. De Salvo S, Bramanti P, Marino S. Clinical differentiation and outcome evaluation in vegetative and minimally conscious state patients: the neurophysiological approach. Funct Neurol (2012) 27:155-62.

8. Schnakers C, Vanhaudenhuyse A, Giacino J, Ventura M, Boly M, Majerus S, et al. Diagnostic accuracy of the vegetative and minimally conscious state: clinical consensus versus standardized neurobehavioral assessment. BMC Neurol (2009) 9:35. doi:10.1186/1471-2377-9-35

9. Teasdale G, Jennett B. Assessment of coma and impaired consciousness. A practical scale. Lancet (1974) 2:81-4. doi:10.1016/S0140-6736(74)91639-0

10. Bordini AL, Luiz TF, Fernandes M, Arruda WO, Teive HA. Coma scales: a historical review. Arq Neuropsiquiatr (2010) 68:930-7. doi:10.1590/S0004282X2010000600019

11. De Santi L, Lanzafame P, Spano B, D’Aleo G, Bramanti A, Bramanti P, et al. Pursuit ocular movements in multiple sclerosis: a video-based eye-tracking study. Neurol Sci (2011) 32:67-71. doi:10.1007/s10072-010-0395-1

12. Trepagnier C. Tracking gaze of patients with visuospatial neglect. Top Stroke Rehabil (2002) 8:79-88. doi:10.1310/RH1W-Y1Y9-4Y8H-E933

13. Pierrot-Deseilligny C. Saccade and smooth-pursuit impairment after cerebral hemispheric lesions. Eur Neurol (1994) 34:121-34. doi:10.1159/000117025

14. O’Driscoll GA, Wolff AL, Benkelfat C, Florencio PS, Lal S, Evans AC. Functional neuroanatomy of smooth pursuit and predictive saccades. Neuroreport (2000) 11:1335-40. doi:10.1097/00001756-200004270-00037

15. Spencer RF, Porter JD. Biological organization of the extraocular muscles. Prog Brain Res (2006) 151:43-80. doi:10.1016/S0079-6123(05)51002-1

16. Johnston K, Everling S. Neurophysiology and neuroanatomy of reflexive and voluntary saccades in non-human primates. Brain Cogn (2008) 68:271-83. doi:10.1016/j.bandc.2008.08.017

17. Lencer R, Trillenberg P. Neurophysiology and neuroanatomy of smooth pursuit in humans. Brain Cogn (2008) 68:219-28. doi:10.1016/j.bandc.2008.08.013

18. Sharpe JA. Neurophysiology and neuroanatomy of smooth pursuit: lesion studies. Brain Cogn (2008) 68:241-54. doi:10.1016/j.bandc.2008.08.015

19. Muri RM, Nyffeler T. Neurophysiology and neuroanatomy of reflexive and volitional saccades as revealed by lesion studies with neurological patients and transcranial magnetic stimulation (TMS). Brain Cogn (2008) 68:284-92. doi:10.1016/j.bandc.2008.08.018

20. Coleman MR, Owen AM. Functional neuroimaging of disorders of consciousness. Int Anesthesiol Clin (2008) 46:147-57. doi:10.1097/AIA.0b013e318181adcc

21. Marino S, Bramanti P. Neurofunctional imaging in differential diagnosis and evaluation of outcome in vegetative and minimally conscious state. Funct Neurol (2009) 24:185-8.

22. Owen AM, Coleman MR. Detecting awareness in the vegetative state. Ann N Y Acad Sci (2008) 1129:130-8. doi:10.1196/annals.1417.018

23. Owen AM, Coleman MR. Using neuroimaging to detect awareness in disorders of consciousness. Funct Neurol (2008) 23:189-94.

24. Machado C, Korein J. Persistent vegetative and minimally conscious states. Rev Neurosci (2009) 20:203-20. doi:10.1515/REVNEURO.2009.20.3-4.203

25. Owen AM. Detecting consciousness: a unique role for neuroimaging. Annu Rev Psychol (2013) 64:109-33. doi:10.1146/annurev-psych-113011-143729

26. Goldberg JM, Fernandez C. Vestibular mechanisms. Annu Rev Physiol (1975) 37:129-62. doi:10.1146/annurev.ph.37.030175.001021

27. Yagi T, Baba S. Evaluation of the brain-stem function by the auditory brain-stem response and the caloric vestibular reaction in comatose patient. Arch Otorhinolaryngol (1983) 238:33-43. doi:10.1007/BF00453739

28. Leigh RJ, Hanley DF, Munschauer FE III, Lasker AG. Eye movements induced by head rotation in unresponsive patients. Ann Neurol (1984) 15:465-73. doi:10.1002/ana.410150511

29. Born JD, Albert A, Hans P, Bonnal J. Relative prognostic value of best motor response and brain stem reflexes in patients with severe head injury. Neurosurgery (1985) 16:595-601. doi:10.1097/00006123-198505000-00002

30. Mueller-Jensen A, Neunzig HP, Emskotter T. Outcome prediction in comatose patients: significance of reflex eye movement analysis. J Neurol Neurosurg Psychiatry (1987) 50:389-92. doi:10.1136/jnnp.50.4.389
31. van den Berge JH, Braakman R, Schouten HJ. Interobserver agreement in assessment of vestibulo-ocular responses. J Neurol Neurosurg Psychiatry (1987) 50:1045-7. doi:10.1136/jnnp.50.8.1045

32. Jacob JT, Burns JA, Dupont SA, Lanzino G, Wijdicks EF. Wall-eyed bilateral internuclear ophthalmoplegia after ruptured aneurysm. Arch Neurol (2010) 67:636-7. doi:10.1001/archneurol.2010.60

33. Weiss N, Tadie JM, Faugeras F, Diehl JL, Fagon JY, Guerot E. Can fast-component of nystagmus on caloric vestibulo-ocular responses predict emergence from vegetative state in ICU? J Neurol (2012) 259:70-6. doi:10.1007/s00415-011-6120-z

34. Schlosser HG, Unterberg A, Clarke A. Using video-oculography for galvanic evoked vestibulo-ocular monitoring in comatose patients. J Neurosci Methods (2005) 145:127-31. doi:10.1016/j.jneumeth.2004.12.004

35. Trojano L, Moretta P, Loreto V, Cozzolino A, Santoro L, Estraneo A. Quantitative assessment of visual behavior in disorders of consciousness. J Neurol (2012) 259:1888-95. doi:10.1007/s00415-012-6435-4

36. Candelieri A, Cortese MD, Dolce G, Riganello F, Sannita WG. Visual pursuit: within-day variability in the severe disorder of consciousness. J Neurotrauma (2011) 28:2013-7. doi:10.1089/neu.2011.1885

37. Dolce G, Lucca LF, Candelieri A, Rogano S, Pignolo L, Sannita WG. Visual pursuit in the severe disorder of consciousness. J Neurotrauma (2011) 28:1149-54. doi:10.1089/neu.2010.1405

38. Bruno MA, Vanhaudenhuyse A, Schnakers C, Boly M, Gosseries O, Demertzi A, et al. Visual fixation in the vegetative state: an observational case series PET study. BMC Neurol (2010) 10:35. doi:10.1186/1471-2377-10-35

39. Balazs S, Stepan C, Binder H, Von Gizycki H, Avitable M, Obersteiner A, et al. Conjugate eye movements and gamma power modulation of the EEG in persistent vegetative state. J Neurol Sci (2006) 246:65-9. doi:10.1016/j.jns.2006. 02.007

40. Oksenberg A, Gordon C, Arons E, Sazbon L. Phasic activities of rapid eye movement sleep in vegetative state patients. Sleep (2001) 24:703-6.

41. Braakman R, Gelpke GJ, Habbema JD, Maas AI, Minderhoud JM. Systematic selection of prognostic features in patients with severe head injury. Neurosurgery (1980) 6:362-70. doi:10.1227/00006123-198004000-00002

42. Trojano L, Moretta P, Loreto V, Santoro L, Estraneo A. Affective saliency modifies visual tracking behavior in disorders of consciousness: a quantitative analysis. $J$ Neurol (2013) 260:306-8. doi:10.1007/s00415-012-6717-x

43. Schnakers C, Giacino J, Kalmar K, Piret S, Lopez E, Boly M, et al. Does the FOUR score correctly diagnose the vegetative and minimally conscious states? Ann Neurol (2006) 60:744-5. doi:10.1002/ana.20919

44. Kane NM, Rowlands K, Nelson RJ, Moss T. Oculographic findings in traumatic unconsciousness: prognostic implications. J Neurol Neurosurg Psychiatry (1995) 59:450. doi:10.1136/jnnp.59.4.450

45. van Woerkom TC, Van Weerden TW, Minderhoud JM. Saccadic oscillations associated with the quick phases of caloric nystagmus in severe diffuse brain damage. Clin Neurol Neurosurg (1984) 86:21-7. doi:10.1016/0303-8467(84)90274-9

46. Pierrot-Deseilligny C, Ploner CJ, Muri RM, Gaymard B, Rivaud-Pechoux S. Effects of cortical lesions on saccadic: eye movements in humans. Ann N Y Acad Sci (2002) 956:216-29. doi:10.1111/j.1749-6632.2002.tb02821.x

47. Herczynski K. Saccadometer - Integrated Research Environment [Online]. (2013) [cited 2013 Dec 22]. Available from: http://www.ober-consulting.com/ 11/lang/1/

48. Engbert R. Microsaccades: a microcosm for research on oculomotor control, attention, and visual perception. Prog Brain Res (2006) 154:177-92. doi:10.1016/S0079-6123(06)54009-9

49. Collewijn H, Kowler E. The significance of microsaccades for vision and oculomotor control. J Vis (2008) 8(20):21-21. doi:10.1167/8.14.20

50. Hicheur H, Zozor S, Campagne A, Chauvin A. Microsaccades are modulated by both attentional demands of a visual discrimination task and background noise. J Vis (2013) 13:18. doi:10.1167/13.13.18

51. Ltd SR. EyeLink 1000-Multiple Eye Tracking Solutions in One [Online]. (2013) [cited 2013 Dec 22]. Available from: http://www.sr-research.com/EL_1000.html

52. Instruments S. Products - IVIEW X ${ }^{\mathrm{TM}}$ HI-SPEED [Online]. (2013). Available from: http://www.smivision.com/en/gaze-and-eye-tracking-systems/products/ iview-x-hi-speed.html

53. Limited NZBR. Eye Movement Lab [Online]. Canterbury Medical Research Foundation. (2013) [cited 2013 Dec 22]. Available from: http://www.nzbri.org/ research/labs/eyelab/equipment.php

54. Rodger M, Ramsay T, Fergusson D. Diagnostic randomized controlled trials: the final frontier. Trials (2012) 13:137. doi:10.1186/1745-6215-13-137 
55. Rosenblatt S. How An Eye-Tracker Can Make Google Glass Less Creepy (Q\&A) [Online]. (2013). Available from: http://www.cnet.com/news/how-aneye-tracker-can-make-google-glass-less-creepy-q-a/

Conflict of Interest Statement: Windsor Kwan-Chun Ting is conducting graduate thesis work using eye-tracking technology in assessment and prognosis of traumatic brain injury. Dr. Michael D. Cusimano has received Canadian Institutes of Health Research Funding to use eye movements to assess traumatic brain injury. Jose Luis Perez Velazquez declares that the research was conducted in the absence of any commercial or financial relationships that could be construed as a potential conflict of interest.
Received: 01 June 2014; accepted: 11 July 2014; published online: 29 July 2014.

Citation: Ting WK-C, Perez Velazquez JL and Cusimano MD (2014) Eye movement measurement in diagnostic assessment of disorders of consciousness. Front. Neurol. 5:137. doi: 10.3389/fneur.2014.00137

This article was submitted to Neurotrauma, a section of the journal Frontiers in Neurology.

Copyright (C) 2014 Ting, Perez Velazquez and Cusimano. This is an open-access article distributed under the terms of the Creative Commons Attribution License (CC BY). The use, distribution or reproduction in other forums is permitted, provided the original author(s) or licensor are credited and that the original publication in this journal is cited, in accordance with accepted academic practice. No use, distribution or reproduction is permitted which does not comply with these terms. 


\section{APPENDIX}

Ovid MEDLINE was searched for peer-reviewed literature meeting specific inclusion/exclusion criteria.

\section{INCLUSION}

Primary clinical studies/case series/letters.

Study conducted in humans.

Patient group must have sustained pathological sustained loss of consciousness (VS, PVS, MCS, or Coma).

Measurement must be quantitative or scaled and conducted during DOC.

Abstract or full text written in English.

\section{EXCLUSION}

Duplicate results

Loss of consciousness due to intoxication (intoxication itself may adversely affect eye movements).

Non-pathological loss of consciousness (e.g., sleep, g-forced induced, anesthesia, Valsalva maneuver loss of consciousness studies).

Studies of locked-in syndrome (patients present with high arousal and awareness).

Study published prior to 1980 .

Reviews or Opinion Articles.
MEDLINE Search Algorithm

Ovid Medline was queried on 20 November 2013 as follows. Database: Ovid MEDLINE(R) (1946 to November Week 1 2013), Ovid MEDLINE(R) In-Process and Other Non-Indexed Citations (November 19, 2013).

\section{Search strategy:}

exp consciousness disorders/ or exp consciousness/(44522)

exp eye movements/(39713)

1 and 2 (313)

remove duplicates from 3 (308)

limit 4 to (English language and humans and year $=" 1980-$ Current") (130)

limit 5 to "review" (20)

5 not 6 (110).

Each abstract was screened with full-text if available. Studies which did not fulfill the inclusion criteria, met the exclusion criteria, or studies for which the full text was not available and the abstract alone was insufficient were removed $(N=91)$. Five articles were automatically removed as duplicates during the search. Thirteen primary research studies were included in the final review. Five case studies and letters were also included, but grouped separately in Table 1. 